\title{
We need tough teachers!
}

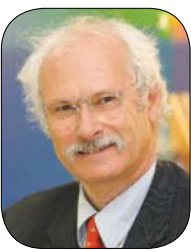

Jean-François ROULET

DDS, Habil, Prof hc, Dr hc, Professor

Editor-in-Chief

Dear Readers,

Following the classical set up of a university according to Humboldt, a University Professor should teach, perform research and service (in practically oriented professions). Teaching is divided in the undergraduate level and graduate level. Both are academic categories of education with the inherent objective that an academic should have the knowledge of his/her profession to be able to participate in the profession's development in the future. This is why in many nations, especially for the so called liberal professions (Physicians, Pharmacists, Lawyers, Architects and Engineers) professional organizations are allowed to participate or even to create and enforce their own professional laws. At graduate level the objective is to train future professors. If no one else, then they should be the ones with the deep knowledge to guide the profession into the future based on the results of their research.

My peers tell me that we are teaching the millennials or the generation $X$, which are different. They are not used to being criticized and do not have an attention span longer than 10 minutes. I am told that teachers must adapt to this, be nice to the students and avoid criticism. The unfortunate result of such an attitude is that we always tell the students what to do. The worse result is that the students ask us what to do, which yields to the situation that students are full of knowledge, pass the boards (multiple choice questions) with flying colours, but are unable to analyze a clinical situation or a research paper by applying their knowledge and "connecting the dots", in other words, they do not have the ability of critical thinking. I have experienced students on the clinical floor that do not know what materials they are using, how they work, which light curing unit they use, what it's irradiation is and which radiant exposure is needed to cure the composite they are using. The same when it comes to prevention. In discussions I literally have to beat out of them the relevant facts they have learned a few years ago and explain the clinical relevance to them. The same in the class I am teaching about learning from the literature.

So what shall we do in this situation? Let the profession degrade to a profession based on vocational training, where the dentist maybe knows what to do, but has no clue why? Shall we allow the information source for the students once they have graduated become the sales representatives, who have only one objective: sell the product that brings them the highest gain, that is converted into their bonus? Leave the future of our profession to be determined by politicians, where quite often the major aim is to be reelected? Shall we close our eyes, when looking at a health care system driven by financial politics and ignore that people die because they cannot afford health care services?

Of course not! And this is the reason why we need tough teachers. In the past, many years ago, I was feared because I was demanding to the undergraduate students. I used to teach concepts and their clinical applications, which is difficult for both the teacher and the student. Therefore the students did not like me, however it happened on numerous occasions that former students, who had become dentists in the meantime, approached me and thanked me for the great concepts and knowledge they got in their "scientific dental package". I was told that they realized only later how much better they were prepared to run their office than their peers. Today, I have completely changed my teaching style on the clinical floor. I do not give instructions any more. If the student asks me what to do, I tell him or her: "I will not tell you! You tell me what you want to do and then we can discuss it". This is the way it should go, because once they have graduated, there is no teacher anymore to tell them (see above). With this, again I am not a much liked teacher and I get poor evaluations from the students. Well I have to live with this, since I am a University Professor and not a trade school teacher!

Sincerely yours,

J.-F. Roulet

Editor-in-Chief 